\title{
Training School Managers Works!
}

\author{
Adrie Visscher, Roel Bosker, Martien Branderhorst \\ 1. University of Twente, The Netherlands, 2. University of Groningen, The Netherlands, \\ 3. Ministry of Education, Culture and Science, The Netherlands
}

\begin{abstract}
Although most secondary schools use management information systems (MISs), these systems are primarily used for clerical purposes and are not used to a significant extent to support higher order managerial activities. This situation is less than desirable, as schools are receiving more discretion in developing school policies and MISs could be offering important assistance in this respect. Our research shows the positive effects of a deliberately designed training course on the knowledge of school managers about MISs, on their attitudes towards MISs, and on the skills school managers need in order to use MISs to support decision-making.
\end{abstract}

Keywords: School management, management information systems, training course.

\section{INTRODUCTION AND PROBLEM STATEMENT}

Most secondary schools use computer-assisted information systems in their organisational operations, however, their use tends to be heavily concentrated in the area of clerical functions (Fung, et al., 2001; Visscher \& Bloemen, 1999). Although this type of assistance is very important, resulting in valuable improvements in efficiency, the information systems (ISs) are not generally applied optimally to the support of higher order managerial work in schools.

The need for informed policy-making has increased in recent years, and it is likely to continue to increase as schools receive more discretion in developing their own school policies (Chubb \& Moe, 1990). This rise in school autonomy means that schools must now develop plans in areas in which they formerly executed policies that had been developed at the national level. In order to make optimal use of this room for policy-making, school staff must acquire information upon which plans and decisions can be based. Management information systems (MISs) may provide a basis for more informed decision-making, as various types of computer-produced information can be used in school decision-making for so-called ill-

Please use the following format when citing this chapter.

Visscher, A., Bosker, R. and Branderhorst, M., 2007, in IFIP International Federation for Information Processing, Volume 230, Knowledge Management for Educational Innovation, eds. Tatnall, A., Okamoto, T., Visscher, A., (Boston: Springer), pp. 89-97. 
structured problems (e.g. the problem that student achievement levels are too low). Ill-structured problems can have a wide variety of potential causes, and various possible problem-solving strategies of unknown effect exist. Structured problems differ from ill-structured problems in the fact that the former type of problem is characterized by a limited number of variables and solutions, and by known strategies for solving them (e.g. the construction of timetables). Problem diagnosis and the search for solutions are crucial in dealing with ill-structured problems, and these can be supported by the output from ISs in four ways (Visscher, 1996):

- Analysing relationships between variables, e.g. between truancy and student achievement; or between achievement and lesson drop out.

- Analysing patterns over time, e.g. in student intake, staff illness, truancy over several years.

- Answering what-if questions, e.g. how many students will be promoted if the student promotion criteria are raised? How much money will the school receive if the number of students decreases by $\%$ ? How many teachers will be needed if students are promoted?

- Information system-based policy evaluation, e.g. to what extent has the percentage of grade repeaters increased since the adaptation of the promotion criteria? Has truancy increased since the changing of the timetable? What was the effect of extra mathematics lessons on student achievement?

If the policy-making and problem solving performed by school managers improves as a result of the utilization of computing power of MISs, this may improve school effectiveness and is therefore something worth striving for.

An analysis of the research on the introduction of computer-assisted ISs into schools shows that the extent of user training significantly influences the degree to which ISs are used. Table 1 shows that 8 factors predict the extent of IS use one or more times in three different studies. Internal and external training are the only two factors predicting direct use (i.e. use by the person him- or herself, as opposed to indirect use by clerical staff retrieving information from an IS for managers) in three studies in Hong Kong, the Netherlands, England. As mentioned above, ISs are used in particular in the clerical context, in other words, training definitely promotes clerical IS use. Whether this also goes for higher order managerial use of school information systems is something in need of further investigation.

Table 1: Predictors of direct system use in three studies (sources: Visscher et al., 1999; Visscher \& Bloemen, 1999; Visscher et al., 2003)

\begin{tabular}{lccc}
\hline & Hong Kong & the Netherlands & England \\
\hline Start motivation & $\mathrm{x}$ & & $\mathrm{x}$ \\
Computer experience & $\mathrm{x}$ & $\mathrm{x}$ & $\mathrm{x}$ \\
Internal training & $\mathrm{x}$ & $\mathrm{x}$ & $\mathrm{x}$ \\
External training & $\mathrm{x}$ & $\mathrm{x}$ & $\mathrm{x}$ \\
IS data quality & $\mathrm{x}$ & $\mathrm{x}$ & \\
Clarity innovation goals & $\mathrm{x}$ & & $\mathrm{x}$ \\
Clarity innovation means & & & \\
Length of personal use & & & \\
\hline
\end{tabular}


There is, however, good reason for focussing on training in order to promote the use of ISs for managerial purposes, as managerial IS use presupposes various skills. Any training course should bring managerial staff to a level at which they are able to decide which information is needed for decision-making, and to interpret the data in such a way that it can be used for developing, implementing, and evaluating decisions and school policies. Managers must learn, for example, what specific data do or do not say, as they are not experienced in interpreting aggregated computer data. Unfortunately, the content of the few principal training courses that do exist tends to be both too technical and too theoretical in nature (Visscher \& Bloemen, 1999).

Given the aforementioned state of affairs, the research conducted in this study was guided by the central question as to whether or not a deliberately designed training course can improve the utilisation of MISs by secondary school principals for purposes of managerial support.

\section{CHARACTERISTICS OF THE TRAINING COURSE}

An important step towards answering the research question involves determining what exactly school managers should be trained for, and how this should be done. This question has been answered by analysing the scientific literature on: a) the implementation of information and communication technologies in education, especially the introduction of MISs; b) strategies for adult training. The literature review indicates (for more details see Bosker, Branderhorst \& Visscher, 2006) that the training course should have the following characteristics:

- Match the nature of the training course with the expertise and skills of participants, starting with problems they face in their professional practise.

- Determine the needs of individual participants at the start, and strive to ensure that participants experience maximal success as quickly as possible.

- Teach participants how to determine the kinds of information they need, as well as how they can select, retrieve, interpret, and use it in school policy-making. To this end, make use of various instructional strategies, including active learning, self-study, and group assignments.

- Promote the transfer of what has been learned to professional practice by offering on-the-job support and involving colleagues in the training course. 


\section{DESIGN OF THE STUDY}

The central research question was answered by investigating whether principals who had followed the designed training course know more about the way the MIS can be used to support decision making, whether they use it more for developing and evaluating decisions, and whether they are more positive about the possibilities offered by the MIS. The effect of the training course was evaluated using the Solomon four-group design:

$\begin{array}{lrrl}\mathrm{R} \mathrm{O} 1 & \mathrm{X} \mathrm{O} 2 & \mathrm{O} 3 & \text { group 1 } \\ \mathrm{R} \mathrm{O} 1 & \mathrm{O} 2 & \mathrm{O} 3 & \text { group 2 } \\ \mathrm{R} & \mathrm{X} \mathrm{O} 2 & \mathrm{O} 3 & \text { group 3 } \\ \mathrm{R} & \mathrm{O} 2 & & \text { group 4 }\end{array}$

$\mathrm{R}=$ the four groups are composed by using randomization procedures

$\mathrm{X}=$ experimental treatment

$\mathrm{O} 1=$ pre-test

$\mathrm{O} 2$ = post-test two weeks after the treatment

$\mathrm{O} 3=$ retention test three months after the treatment

In the Solomon four-group design, the classical pre-test post-test controlgroup design is augmented by two extra groups in order to control for the sensitising effect of the pre-test and for any interaction between pre-test and treatment (Philips, 1976; Swanborn, 1999). By adding the retention test, it was possible to determine how and to what extent the effect of the treatment was maintained over a period of three months. In practice, all groups were trained in the end. The school leaders that made up group 2, for instance, were tested at $\mathrm{O} 1$ and $\mathrm{O} 2$, after which they became part of group 1, for whom $\mathrm{O} 2$ was the pre-test. For that reason there were four time points: at $\mathrm{T} 1$ a pre-pre-test, at $\mathrm{T} 2$ a pre-test, at $\mathrm{T} 3$ a post-test, and at $\mathrm{T} 4$ retention test.

Currently, three MISs are in use in the majority of Dutch secondary schools. At the time of the study, however, only one MIS, called School+ Web, could generate information to support the management activities of principals (this is another indication of the clerical focus in the support given by ISs in schools) and was therefore chosen as the MIS for which trainees would be trained in the training course.

Data was collected through a written questionnaire. Because of the lack of prior research on the principals' use of MISs for decision-making tasks, it was necessary to develop a questionnaire. This questionnaire was meant to distinguish between three elements of the dependent variable 'the degree of MIS use': knowledge of the MIS, skills in MIS use, and the MIS attitude (factor analysis supported the existence of these three factors, which explained a total of $52 \%$ of the variance).

In addition to the three scales (reliability varied between 0.87 and 0.96 ), the questionnaire included variables that were expected to be related to the dependent variables (for example, age, experience with computers, school size). Principals were also interviewed in order to gather more information 
about the transfer of skills and knowledge acquired as well as to examine the extent to which these managers generate management information and use it for the policy process.

Managers of schools using School+ Web were informed of the existence of the training course. Those who wanted to follow the training course were assigned randomly to one of the four groups of the Solomon design. The groups can therefore be assumed to be comparable.

With regard to obtaining a sample of sufficient size and scope, data collection took place in the period between autumn 2002 - spring 2004. A total of sixty-one respondents participated in the study (response rate $95 \%$ ); the number of respondents per Solomon group is: group $1=12$; group $2=$ 13; group $3=18$; group $4=18$.

The groups of respondents consist mainly of men of an average age of 49. The average size of the schools involved is 1500 pupils. The respondents' use of the computer is very intensive, but that does not apply to the use of management information. Furthermore, the respondents' knowledge and skills in the field of School + Web are limited. The four Solomon groups appear to be strongly comparable on the context variables.

Analysis of variance and t-tests (level of significance was set at 0.10 onesided) were used to test the significance of pre-existing differences between various groups. Multilevel models (two levels: moment of measurement, and trainee) were applied to test whether the experimental treatment was related to differences in the growth trajectories of the trainees. (Snijders \& Bosker, 1999).

\section{RESULTS}

The results presented here offer an answer to the question as to whether a deliberately designed training course can improve the utilisation of MISs for managerial support. In more operational terms, data analysis focused on finding out whether the training course produces differences in the knowledge about, attitudes towards, and skills in the use of the MIS between the experimental group and the control group.

The general hypothesis is that, as a result of the training course, the members of the experimental group are more knowledgeable about which information can be retrieved from School+ Web, have a more positive attitude towards the use of the MIS, and have better skills in using MIS than the members of the control group.

\subsection{Knowledge}

The difference between the experimental and control groups with regard to the knowledge about the management information that the MIS can retrieve was statistically significant, not only at the end of the training $(t=$ 
$3.50 ; \mathrm{p}<0.001)^{1,2}$ but also a few months later $(\mathrm{t}=4.10 ; \mathrm{p}<0.001)$. These differences remained when controlling for differences in knowledge between participants at the start of the training. The analyses further revealed no significant interactions between treatment and pre-test $(t=-1.47 ; \mathrm{p}=0.144)$.

The effect size $^{3}$, the power of a test after the experiment has been performed (T3 vs T2), is 0.80 . For the retention test (T4 vs T2)), the effect size is 0.83 . According to Cohen (1988), both effects are large ${ }^{4}$.

\subsection{Attitude}

The effect of the training (T3 vs T2) on the attitude towards MIS use appeared to be significant $(\mathrm{t}=2.03 ; \mathrm{p}=0.044)$, with an effect size of 0.44 . After a few months, however, the effect (T4 vs T2) had disappeared ( $t=0.50$; $\mathrm{p}=0.62$ ). In other words, at that time, the attitudes of the members of the control group were the same as those of the experimental group. No significant interactions were observed between treatment and pre-test $(\mathrm{t}=-$ $1.20 ; \mathrm{p}=0.22$ ).

\subsection{MIS use}

The analyses of the data concerning the use of the information system for decision support revealed that the mean score of the experimental group is significantly higher than that of the control group, taking scores on the pretest into account $(t=2.82 ; p=0.006)$, with a medium effect size of 0.52 . After a few months (T4 vs T2), this difference was smaller, but still significant $(t=2.00 ; p=0.05)$, with an effect size of 0.33 . There were no significant interactions between treatment and pre-test $(t=-0.48 ; p=0.63)$.

\subsection{Covariates}

The questionnaire included several contextual variables that were expected to be important for the use of ISs for managerial activities. The analyses, however, revealed no differences between the experimental and control groups for these variables, with the exception of the variable 'school size'. Because this difference could have influenced the results of the analyses, the analyses were conducted once more with school size as a covariate. School size was found to have a significant effect on the use of

In the empty model, the mean and variance are estimated. In the model, T2 is taken as the contrast for the time points.

2 For studying the significance of effects, the t-ratio has been computed with 50 degrees of freedom (there were 111 degrees of freedom for the interaction effects).

3 The effect size has been computed by dividing the regression coefficient by the square root of the total variance, which is the residual pooled standard deviation.

4 Cohen defines an effect size of 0.8 as large; an effect size of 0.5 as average, and an effect size of 0.2 as small. 
the MIS ${ }^{5}$ t the treatment effect for principals in smaller schools was greater than for principals in larger schools.

\subsection{Interviews}

The main conclusion of the interviews is that, after completing the training, principals expected to be able to use information from School+ Web for decision support, but that all users experienced problems with the information system. Because of technical problems, the MIS failed to meet expectations. The attitudes of the users concerning the possibilities of using School + Web for developing, implementing and evaluating decisions and school policies had therefore become less positive.

\section{CONCLUSION}

The results of this study reveal that members of the experimental group are more knowledgeable about which management information the MIS can retrieve, are more positive about the use of MIS, and are more skilled in using the MIS for decision support. However, some months after having completed the training, the attitude of the manager with respect to the use of management information is less positive than a few weeks after the training.

Whether or not the research results may have been caused by the pre-test, or by an interaction between the pre-test and the intervention, was also examined. Although the research results show that the training course has a little more effect if a pre-test has been taken, this effect does not prove to be significant.

The effect of the relevant context variables on the difference between the groups was also analysed and found to be only marginal. It appears that the training effect is somewhat larger when the school is smaller. An explanation for this finding may be that quantitative management information receives less attention in a small school compared with a large school because school managers in small schools have a good overview of how the school functions without that information. As a result, the training course may have more of an effect on the use of management information in small schools because of the prior use was more limited there. However, including the 'school size' variable in the multilevel model does not lead to other outcomes when testing the hypotheses.

In this study, a training course was developed, based on a literature review and in consultation with school managers, with the expectation that it would produce the desired effects. This training course took into account the

5 The variable 'school size' has been centered around the general mean to facilitate the interpretation of findings. 
individual needs of the participants and was designed to fit with the actual work practice of school managers. Unfortunately, the planned training follow-up activities, such as organizing a follow-up day, did not take place. Such activities are, however, important for the transfer of training to work practice. Furthermore, some participants found the differences between the training participants too large in terms of their knowledge of School+ Web, and the degree to which school policies were developed within their schools (before they were trained). It would be interesting to optimize the training course in order to address these shortcomings and to examine whether the training effect would then be even greater.

Now that we know that training courses with specific characteristics have very positive effects on the use of MISs in schools in terms of knowledge, attitude, and skills, the next step should be to conduct more longitudinal research into the question concerning whether a more intensive use of MISs leads to better decisions, and, eventually, to more effective schools.

To which target groups can the research results be generalized? The 'objective population' includes managers of secondary schools who work with a computer-assisted information system and who have an interest in the utilization of management information. However, the experiment was carried out with the information system School+ Web, and the sample was therefore limited to Dutch managers with an interest in management information working in schools that use School+ Web. Theoretically, the generalizability of the results is limited. However, on the basis of interviews with a number of school managers who use a different MIS than School+ Web and who did not participated in the training course, it seems that the use of management information from other information systems is very limited, but that, at the same time, the interest in the subject is growing. With the training course central to this study, it might be possible to promote the use of other MISs. Most schools are still in the implementation stage and, as a result, do not prioritize its use for management information. When they have fully implemented a MIS, it will be interesting to evaluate the impact of a training course like the one we have studied in this project.

Principals make many decisions under conditions of uncertainty. They are burdened with information and have little time to process or reflect on the information. Full rational behaviour, in terms of choosing the best way to achieve explicit goals after having processed relevant information, is rare (Riehl et al., 1992). Principals also do not frequently evaluate the performance of their schools in terms of trends and results. It is therefore not surprising that MISs are not yet used much for higher order decisionmaking. The results of this research project provide empirical evidence for the assertion that carefully designed training courses can stimulate principals to use MISs for decision support in schools. Hopefully, our findings will encourage and support others responsible for the design and implementation of MISs to improve the quality of management activities within schools. 


\section{REFERENCES}

Akker, J. van den, Keursten, P. and Plomp, T. (1992). The integration of computer use in education. International Journal of Educational Research, 17, 65-76.

Baldwin, T.T. and Ford, J.K. (1988). Transfer of training: a review and directions for future research. Personnel Psychology, 41, 63-105.

Bosker, R.J., Branderhorst, E.M. and Visscher, A.J. (submitted for publication). Improving the utilization of management information systems in secondary schools. Journal of Educational Research.

Chubb, J.E. and Moe, T.M. (1990). Politics, Markets and American Schools. Brooking Institute, Washington, DC.

Cohen, J. (1988). Statistical power analysis for the behavioral sciences. Hillsdale: Lawrence Erlbaum Associates.

Fung, A., Visscher, A., Smith, D. and Wild, P. (2002). Comparative evaluation of the implementation of computerised school management systems in Hong Kong, The Netherlands and England. In D. Watson and J. Andersen (Eds.), Networking the learner, Computers in Education (pp. 591-600), Boston/Dordrecht/London, Kluwer Academic Publishers.

Phillips, B.S. (1976). Social research; strategy and tactics. New York: Macmillan Publishing.

Riehl, C., Pallas, G. and Natriello, G. (1992). More responsive high schools student information and problem-solving. Paper presented at the Annual Meeting of the American Educational Research Association, San Francisco.

Snijders, T.A.B. and Bosker, R.J. (1999). Multilevel analysis: an introduction to basic and advanced multilevel modeling. London: Sage.

Swanborn, P.G. (1999). Evalueren. Het ontwerpen, begeleiden en evalueren van interventies: een methodische basis voor evaluatie-onderzoek. [Evaluation, Designing, supervising and evaluating interventions: a methodological base for evaluation research.] Amsterdam: Boom.

Visscher, A.J. (1996). Information technology in educational management as an emerging discipline. International Journal of Educational Research, 25(4), 291-296.

Visscher, A.J., \& Bloemen, P.P.M. (1999). Evaluation and use of computer-assisted management information systems Dutch schools. Journal of Research on Computing in Education, 32(1), 172-188.

Visscher, A.J., Fung, A. and Wild, P. (1999). The evaluation of the large scale implementation of a computer-assisted management information system in Hong Kong schools. Studies in Educational Evaluation, 25, 11-31.

Visscher, A., Wild, P., Smith, D. and Newton, L. (2003). Evaluation of the implementation, use and effects of a computerised management information system in English secondary schools. British Journal of Educational Technology, 34(3), 357-366. 